\title{
Higher, Faster, Further: Occupational Ethical Decision-Making under Time Pressure in Type A versus Type B Personalities
}

\author{
Ann-Kathrin Emser, Simon Heintzen, Claas Beeser, Barbara Stoberock*, Nicki Marquardt \\ Hochschule Rhein-Waal, Kamp-Lintfort, Germany \\ Email: *barbara.stoberock@hochschule-rhein-waal.de
}

How to cite this paper: Emser, A.-K., Heintzen, S., Beeser, C., Stoberock, B., \& Marquardt, N. (2021). Higher, Faster, Further: Occupational Ethical Decision-Making under Time Pressure in Type A versus Type B Personalities. Psychology, 12, 1678-1710. https://doi.org/10.4236/psych.2021.1210102

Received: August 24, 2021

Accepted: October 26, 2021

Published: October 29, 2021

Copyright $\odot 2021$ by author(s) and Scientific Research Publishing Inc. This work is licensed under the Creative Commons Attribution International License (CC BY 4.0).

http://creativecommons.org/licenses/by/4.0/

(c) (i) Open Access

\begin{abstract}
The current study aims to provide insights into personal and situational influencing factors of ethical decision-making in the work context. Previous research has indicated that individuals who are characterized by the so-called Type A personality pattern show increased levels of morality when having to decide on ethical issues. Among others, these people are marked by their great sense of time urgency and their overall preference for speed. As fast decisionmaking often plays a crucial role in businesses, the current study investigated in how far time pressure affects ethical decision-making of Type As in comparison to others (Type Bs). Therefore, we conducted a vignette-based experiment with a $2 \times 2$ between-subjects design. Participants were classified into Type A versus B personalities and had to execute ethical decision-making either with or without time constrains. Results reveal no significant differences in Type As versus Type Bs ethical decision-making regarding four different moral domains, namely moral awareness, moral judgement, moral intention, and moral behavior. Results indicate numerically stricter moral judgement and higher moral intentions of Type As (versus Bs), while failing to reach statistical significance. Additionally, our results revealed significant negative associations between time pressure and (only) one moral domain, namely moral behavior, indicating more moral behavior within participants without time pressure. These results are in accordance with several studies showing impaired ethical decision-making in individuals that are put under time constraints. Overall, results reveal no significant interaction effects. Practical implications of the results, as well as ideas for future research, are discussed.
\end{abstract}

\section{Keywords}

Ethical Decision-Making, Morality, Time Pressure, Type A Personality, 
Moral Judgment, Personality, Unethical Behavior

\section{Introduction}

"The imperatives of day-to-day organizational performance are so compelling that there is little time or inclination to divert attention to the moral content of organizational decision-making." (Sims, 1992: p. 505).

What happens when no attention is diverted to ethical issues in organizational contexts can be observed in Volkswagen's emission scandal as well as more recently in the scandal evolving around the German corporation of WireCard. After the Philippine Banks BPI and BDO claimed that the WireCard documents detailing $€ 1.9 \mathrm{bn}$ in balances are counterfeit, the scandal began to unfold in June 2020 (McCrum, 2020). Subsequently, former CEO Markus Braun resigned and was arrested shortly after (McCrum, 2020). Former CSO Jan Marsalek is still on the run and presumably hiding in Russia (Zajonz, 2020). But not only the former WireCard executives are suspected to have acted fraudulently or at least inaccurately. Several federal and private corporations, including the Federal Financial Supervisory Authority (BaFin) and the professional accounting services network of Earnest \& Young (EY) presumably failed to look closely enough and neglected to inspect WireCard's documents precisely (Storbeck, 2020; Zajonz, 2020). Consequently, the share price as well as WireCard itself collapsed, and the resulting financial damage is estimated to be at least $€ 3.2 \mathrm{bn}$ (Zajonz, 2020). Additionally, the reputation and credibility of WireCard and involved audit corporations are called into question and severely damaged (Zajonz, 2020).

The WireCard scandal lines up with a bulk of ethical scandals observed over the last decades (Brown \& Treviño, 2006; Knights \& O'Leary, 2005). In the present case, it becomes obvious that multiple executives of WireCard as well as employees of audit corporations acted unethically, thereby damaging investors, corporations, and the credibility of all parties involved. Such scandals evoke the questions: Why is unethical behavior so common in big companies and what factors endorse the occurrence of unethical behavior in individuals? Looking at the scientific literature, it seems that numerous personal and situational factors affect the ethical behavior of individuals in complex interactions (Brown \& Treviño, 2006; Craft, 2013). For example, when being in a positive mood, people often judge ethical issues more lenient compared to a judging while being in a negative mood state (Valdesolo \& DeSteno, 2006). On the other hand, people tend to make more strict moral judgments with their eyes closed versus open, because it induces them to mentally simulate events more extensively (Caruso \& Gino, 2011). It is imperative to further analyze multiple personal, contextual, and moderating influences to fully grasp ethical behavior (Brown \& Treviño, 2006).

In this line, the present research focuses on the effects of two factors, which are particularly important in the occupational context. On the one hand, our re- 
search aims to shed light onto the impact of different types of personality on ethical behavior (Type A versus Type B personality, see Feinleib et al., 1978; Matthews, 1982). On the other hand, our research tries to examine the contextual factor of time restrains on ethical decision making. Research in this underrepresented domain might improve the understanding of ethical decision-making and could invigorate the prevention of prospective ethical scandals.

\section{Theoretical Background}

Unethical behavior in organizations is "embarrassingly commonplace." (Sims, 1992: p. 507; see also Moore \& Gino, 2015). According to Sims (1992) unethical behavior is often expected by executives, and many organizations even reward behavior violating ethical standards if it supports financial success. Too often, profitability and ethicality are displayed as seeming contradictions, while both should be combined in an ethical way of management (Jamnik, 2011; Moore \& Gino, 2015; Sims, 1992). Several studies underline the difficulties of controlling unethical behavior. Many organizations employ a Code of Ethics as a measure to limit unethical behavior "[...] and all too often that is that." (Sims, 1992: p. 506). Problems result from the apparent discrepancies between the Code of Ethics and actual unethical behavior of the organization's employees (Badaracco \& Webb, 1995; Sims, 1992). When combining the high complexity of an individual's ethical decision-making process with the suboptimal efforts of organizations to contain unethical behavior, it becomes obvious that organizations should focus more on the contextual and personal factors affecting their employees (Craft, 2013; Sims, 1992).

According to Jones (1991) as well as Brown and Treviño (2006), it is crucial that individuals realize that they are moral agents, thereby acting in situations where moral issues are at stake. As Jamnik (2011) stresses, most decisions faced by employees are morally relevant. Following, a disregard of ethical orientation will presumably elicit unethical behavior (Brown \& Treviño, 2006; Jamnik, 2011). Typical values that are conflicting in moral dilemmas are on the one hand personal interests and companies' profit, and the other hand personal morality and social responsibility (Moore \& Gino, 2015; Sims, 1992). It is therefore imperative to identify factors that endorse or hinder the ethical orientation and execution of ethical decisions in individuals. The present study therefore aims to further investigate such influences by examining the effects certain types of personality as well as time restraints might have on the ethical decision-making process in the workplace.

\section{Ethical Decision-Making}

Ethical decisions are present in everyone's daily life. By implication, most of us will act as moral agents in many day-to-day situations. In the occupational context, one might have to decide to interrupt ongoing bullying in the work group or must place decisions which are not beneficial to affiliated persons. 
Research has shown that these important ethical decisions are based on four consecutive steps (Rest, 1986), namely moral awareness, judgement, intention, and behavior. The related Four-Component model of Rest (1986) provides the fundamental theoretical concept for many studies on ethical decision-making (Craft, 2013; O'Fallon \& Butterfield, 2005), and corresponds to these four components.

The first component, moral awareness, describes an individual's ability to identify if the consequences of an action will be morally relevant and thereby affecting others (Rest, 1986). An ethical decision-making process will not start without the subject recognizing a situation as moral (Hunt \& Vitell, 1986; Jones, 1991). Jones (1991) stresses that a moral agent who fails to recognize the moral issue might therefore act unethically without realizing. In the process of moral awareness, implicit cognitions and accompanying affective arousal are deeply intertwined, leading to gut feelings and instant first impressions (Rest, 1986).

In the second step, moral judgement, the individual evaluates the gathered information regarding the moral issue and judges the rightness and fairness of a solution (Rest, 1986). Following Rest (1986), the individual's social experiences elicit various concepts of cooperation which then operate like heuristics in guiding the solving of problems. When judging a moral situation, individuals therefore need to prioritize different interests and consider the solution with the highest subjective fairness (Rest, 1986). Jones (1991), in contrast, argues that moral reasoning is greatly dependent on the context. The author further proposed that moral intensity, and thereby factors like social consensus or magnitude of consequences, greatly influence the moral reasoning of individuals, making it issuedependent. Moral philosophy, which is also proposed as an important factor in the ethical decision-making model by Hunt and Vitell (1986), integrates reasoned and nonreasoned processes with deontological and utilitarian judgement (Gawronski \& Beer, 2017). According to the teleological/utilitarian orientation, an action is desirable if it causes overall well-being, while a decline of well-being for all affected people results in an action that's morally not acceptable (Gawronski \& Beer, 2017; Hunt \& Vitell, 1986). In deontology instead, an action is only then morally right if it is concordant with the appropriate moral norms (Gawronski \& Beer, 2017; Hunt \& Vitell, 1986). The moral orientation carries high relevance in ethical decision-making because decision-makers might employ differing ethical orientations and nonetheless both judgements might be perceived as morally appropriate. When examining studies, deontology and idealism were often positively associated with ethical decision-making, while utilitarianism and relativism were often negatively related (Craft, 2013; Musbah et al., 2016; O’Fallon \& Butterfield, 2005).

In the third step, moral intention, individuals indicate their preference about what they are going to do. In moral intention, the moral values assessed in the step of moral judgement might conflict with personal values like self-serving motives (Rest, 1986). Rest (1986) also mentions cognition and affect as contributing 
factors in the third component, showing that positive affect towards the goal or positive mood greatly influence the preference. An individual's moral intention might therefore deviate from the moral judgement assessed in the second step.

Finally, during the fourth step, moral behavior, the individual must execute a final action (Rest, 1986). Following Rest (1986), one must “[...] have sufficient perseverance, ego strength and implementation skills to be able to follow through on his/her intention [...]" (pp. 3-4).

It is important to note that the four components are distinct steps and high moral orientation in one step does not axiomatically result in coincidence with the other components (Rest, 1986). Factors like self-serving values and negative affect might therefore lead to an unethical intention, even though the individual's moral judgement was ethical (Rest, 1986). Furthermore, moral behavior often demands high effort and individuals lacking for example perseverance, might therefore fail to act morally (Rest, 1986). Jones (1991) adds that situations where high moral issues are at stake will more likely elicit moral behavior.

Following, various studies provide further information regarding issue-dependent variables. Sweeney \& Costello (2009) supported the notion that the nature of an ethical scenario influences the ethical decision-making process. As already proposed by Jones (1991), a situation itself and its attending characteristics can impact all four components of ethical decision-making through moral intensity. Various studies supported the notion that moral intensity was significantly associated with ethical awareness, judgement and intention, in occupational settings as well as in general (May \& Pauli, 2002; McMahon \& Harvey, 2007; Musbah, et al., 2016; Paolillo \& Vitell, 2002; Shafer et al., 2001; Shawver et al., 2015; Singhapakdi et al., 1996; Sweeney \& Costello, 2009).

Moreover, individual factors also affect ethical decision-making in the occupational context. Whereas gender elicited mixed results, personality traits and values seem to play an important role (Craft, 2013; O'Fallon \& Butterfield, 2005). Factors like empathy (Brown et al., 2010) and moral emotions (Baker, 2017; Jeong et al., 2020) showed positive associations with ethical decision-making. On the other hand, factors like hedonic emotions (Jeong et al., 2020), machiavellianism (Verbeke et al., 1996) and high ego-strength (Haines \& Leonard, 2007) were negatively associated. Observing underlying mental processes, especially implicit attitudes significantly predicted important components of ethical decision-making, as well as the weighting of decision criteria (Marquardt, 2010; Marquardt \& Hoeger, 2009).

When making a moral decision, organizational environment and the perceived expectation of supervisors also can significantly influence this process (Sims \& Keon, 1999). Interestingly, people have stronger feelings of discomfort when their values are not conforming with informal policies, or experience a higher intrapersonal role-conflict, when they are disagreeing with informal policies or supervisor's expectations (Sims \& Keon, 2000). Hence, social pressure seems to be strongly associated with decision-making as well (Sweeney \& Costello, 2009). 
In conclusion, the ethical decision-making process is greatly influenced by dispositional, situational, and organizational variables in various ways. The present research aims to go further and sheds light on other dispositional and situational variable in the occupational context. On the one hand, the focus lies on the dispositional factor personality and compares different types of personality (Type A versus Type B) regarding ethical decision making in the work context. On the other hand, the situational variable time, or more specifically time pressure, is examined in its relation to ethical decision making.

\section{Ethical Decision-Making under Time Pressure}

Time pressure is arguably one of the most prominent challenges in modern everyday life as well as in the business world. Time pressure a forceful or even threatening situation, influencing individuals or groups, and possibly causing worry or fear (Roxburgh, 2004). Time pressure is often defined as a component of stress (Moberg, 2000) and this thesis is further supported by the study of Chamberlain and Zika (1990), in which time pressure was the most often mentioned daily stressor in most of the examined groups. Additionally, time pressure is repeatedly associated with perceived feelings of being stressed in various studies (Ackerman \& Gross, 2003; Chamberlain \& Zika 1990; Moberg, 2000; Prem et al., 2017; Zuzanek, 2004). In an investigation of the historical development of time pressure, Zuzanek (2004) discovered that it is indeed a very contemporary and serious challenge. In his study, he showed that paid and unpaid workload increased in the decade from 1981-1998 and that time for personal needs, hobbies, and free time itself decreased. The causes for this development seem to be rooted in social and structural trends, more precisely in the increasingly spedup, competitive and globalized (economic) world (Zuzanek, 2004). These increasing demands lead to associations of time pressure and time deprivation with physical health conditions, decreased mental health, the use of anti-depressant drugs, depression, and decreased satisfaction with health and life (Ackerman \& Gross, 2003; Chamberlain \& Zika, 1990; Roxburgh, 2004; Teuchmann et al., 1999; Zuzanek, 2004).

In studies examining the propensity of students to plagiarize, time pressure increased the propensity significantly (Koh et al., 2011, 2018). A meta-Analysis of Belle and Cantarelli (2017) found time pressure to be strongly related to unethical behavior in several studies. In an organizational context, Andiappan and Dufour (2016) observed that individuals take more self-serving choices when put under time constraints.

Moreover, it is important to note that unethical behavior is based on a complex ethical decision-making process, as shown above. Researchers have agreed that different variables can influence the rather complex relationship between time pressure and decision-making processes. Unfortunately, results regarding the influence of time pressure on decision-making are not always consistent. Many studies report detrimental effects of time pressure on decision-making, 
thereby increasing reaction times, decreasing effectiveness, and drastically increasing error rates (Ahituv et al., 1998; Kocher \& Sutter, 2006; Maule \& Edland, 1997; Sütfeld et al., 2017; Zakay \& Wooler, 1984). On the other hand, some studies also report no significant or even positive influences of time pressure on several measures of decision-making (Ahituv et al., 1998; Maule \& Edland, 1997, 2000; Moberg, 2000).

When making decisions under time pressure, individuals employ different habitual or learned strategies to reach a high efficiency (Maule \& Edland, 1997; Maule et al., 2000). The most prominent micro-strategies observed by Maule \& Edland (1997) in decision-makers are acceleration (i.e., increased speed of information processing) and filtration (i.e., focusing on the most important cues). If the decision-maker fails to focus on relevant cues this could lead to inefficient decision-making and maybe also unethical behavior (Moberg, 2000). Nonetheless, quite a few studies discovered that individuals successfully employed acceleration and filtration strategies, meaning that under time-pressure, more relevant cues were detected and sometimes even in a shorter period of time (Dror et al., 1999; Kocher et al., 2006; Stenmark, et al., 2010).

The inconsistent findings regarding decision-making effectiveness and use of strategies can be explained by different personal and contextual variables, changing the influence of time pressure. According to Moberg (2000), scenarios high in complexity and uncertainty will lead to negative performance, because under time pressure less cognitive resources for complex rules or calculations are available. The results of several studies support the notion that the high cognitive load of decision-makers under time pressure influences the choice of strategies, processing of information, and overall performance (Byrne et al., 2015; Maule \& Edland, 1997; Moberg, 2000; Ordóñez \& Benson, 1997). Individual factors leading to impaired decision-making-in situations demanding a high cognitive load because of time pressure-seem to be insufficient experience (Ahituv et al., 1998), a low need-for-cognition (Verplanken, 1993), and high neuroticism (Byrne et al., 2015). On the other hand, individual factors improving decision-making under time pressure are positive cognitive appraisal (Prem et al., 2017), feelings of control (Kühnel et al., 2012; Teuchmann et al., 1999), and quality of forecasting the consequences of the decision (Stenmark et al., 2010). Additionally, the influence of time pressure often takes an inverted U-shape, whereby high and low pressure lead significantly more to detrimental effects on measures of performance (Dror et al., 1999; Moberg, 2000). Especially the influence of appraisals stresses the notion that time pressure is a subjective experience and should optimally be defined from the perspective of the affected person (Maule \& Edland, 1997; Moberg, 2000).

Consequently, we conclude that time pressure is a contextual variable influencing ethical decision-making processes. This multiplex interaction again is strongly affected by a set of personal and situational variables depending on the decision-maker and their circumstances. 


\section{Type A Personality}

So far, we underlined how important personal variables are in interaction with ethical decision-making as well as time pressure. The expansive reviews of O'Fallon and Butterfield (2005) and Craft (2013) stressed that personal variables were the single most important factor influencing the ethical decision-making in the examined studies. Furthermore, various studies supported the notion that personal variables such as neuroticism (Byrne et al., 2015), need-for-cognition (Verplanken, 1993), and coping styles (Prem et al., 2017) account for a great part of variance when explaining performance under time pressure. In the present study we will scrutinize the influence of such a personality variable, namely Type $A$ personality.

The Type A behavior pattern emerged in the 1950's as an epidemiological construct, in relation with patients suffering from coronary heart disease (CHD) (Feinleib et al., 1978; Matthews, 1982). Thus, the concept of coronary-prone behavior was developed (Jenkins et al., 1967). The characteristics were described as “[...] intense striving for achievement, competitiveness, aggressiveness, pressures for vocational activity, excessive sense of time urgency, impatience and restlessness." (Jenkins et al., 1967: pp. 377-378). The counterpart of Type As are Type Bs who seem to lack these traits (Rosenman, 1978). Due to the increasing importance and the high expenditure of measuring Type A with structured interviews (SI), the Jenkins Activity Survey (JAS) was developed for faster prognosis in research and health programs (Jenkins et al., 1967). The assessment of Type A personality with the SI and JAS lead to inconsistencies because the two measures seem to capture different aspects of the construct (Harding \& O'Looney, 1986; Matthews, 1982; Matthews et al., 1982). Hence, when examining Type A personality, it is crucial to distinguish between results that stem from either the SI or the JAS (Matthews, 1982; Thoresen \& Powell, 1992).

Furthermore, some do treat Type-A as a global construct, while it needs to be seen from a multidimensional point of view, as the subcomponents give more accurate information about relations and their directions (Bluen et al., 1990; Burns \& Bluen, 1992; Hart, 1997; Matthews, 1982; Lee et al., 1993; Vera-Villarroel \& Sánchez, 2004). The combination of differing measurements and the complex multidimensionality explain the inconsistent results regarding Type A personality. Additionally, it is important to note that several studies propose that Type A is not a trait in its classical sense, but merely represents a set of behaviors and cognitive strategies to rapidly and successfully cope with high demands (BenZur \& Wardi, 1994; Glass, 1980).

Type A individuals seem to display the three characteristics of achievementstriving, aggressiveness, and time urgency. In the present study the SJAS is employed, and therefore only achievement-striving and time urgency are measured (Matthews, 1982). It is nonetheless important to elucidate all three components to underline the high complexity of Type As. 
The achievement striving component of Type As is directly reflected in their constant need to prove themselves, setting of difficult goals, ambition, and superior performance (Matthews, 1982; Rayburn \& Rayburn, 1996). This notion is underlined by positive correlations of achievement striving with college students' performances (Barling \& Charbonneau, 1992; Lee et al., 1993; Spence et al., 1987). Beyond the results regarding students, achievement striving (AS) is also found as a factor in work environment, e.g. as a predictor for sales performance of insurance brokers (Bluen et al., 1990). Type A individuals typically want to reach their goals in a very short time frame (Rayburn \& Rayburn, 1996). Correspondingly, the high competitiveness of Type A individuals seems to predict a faster reaction time and fewer errors (Pérez-Garcia \& Sanjuán, 1996). Another finding in terms of work is high AS as a predictor of higher job satisfaction (Bluen et al., 1990; Day \& Jreige, 2002). High AS individuals are further linked to a stronger degree of job control and thus appear to have fewer problems with job stressors (Day \& Jreige, 2002). Following, lower ambiguity or role conflict among AS individuals is found (Day \& Jreige, 2002). Competitiveness was also found as a significant predictor of less fear of negative evaluation by others and thus less social avoidance and distress was observed in male Type As (Vera-Villarroel \& Sánchez, 2004). Moreover, the way of coping of Type As with higher AS is found to be more problem-oriented, which might explain their good results regarding shortterm goals (Lee et al., 1993: p. 154). On the other hand, Type As seem to experience high stress due to their competitiveness, resulting in a higher stress in situations with strong interference (Chinaveh, 2014; Pérez-Garcia \& Sanjuán, 1996). Generally, Type As seem to mostly ignore such internal information such as feelings of fatigue in challenging situations (Glass, 1980; Pérez-Garcia \& Sanjuán, 1996).

The second component of Type A personality is aggressiveness and hostility (Glass, 1977). The aggressiveness of Type As seems to be explained by interactions of a high need for control, competitiveness, and the goal to keep a high self-esteem (Rayburn \& Rayburn, 1996). Many studies report that Type As exhibited aggressiveness when their situational control was in danger (Krantz et al., 1974; Rayburn \& Rayburn, 1996; Strube \& Werner, 1985). The lack of control is perceived as a threat and Type As react with behavior such as defensive attributions, effort to gain control or refusal to relinquish control, even if others are objectively superior (Glass, 1980; Pérez-Garcia \& Sanjuán, 1996; Strube \& Werner, 1985). Accordingly, they perceive factors like competition as an important cause of conflict and are less likely to solve conflicts with accommodation (Baron, 1989). Several studies stress the importance of contextual factors like uncontrollability in Type A aggressiveness and it seems that Type As are not inherently more aggressive (Carver, 1980; Glass, 1980; Krantz et al., 1974). The aggressiveness seems to be further linked to the competitiveness of Type As. As lack of control and dangers to their self-esteem are perceived as threats to their success and goals, the competitiveness might therefore result in hostile behavior (Rayburn \& 
Rayburn, 1996; Strube \& Werner, 1985).

As mentioned by Rayburn and Rayburn (1996), Type As want to reach their goals in the shortest period possible. This behavior is explained by the third factor, namely time urgency. Rayburn and Rayburn (1996) described Type As as "chronic hurriers" (p. 1212) because they appear tense and energetic, constantly competing with others and even themselves. Accordingly, they exhibit an accelerated speed of behavior, speech, and level of activity, including activities like eating or walking (Rosenman, 1978; Matthews, 1982). Rosenman (1978) further describes Types A as “[...] excessively punctual and time-oriented” (p. 60). Their high time urgency leads to superior performance under time pressure in many studies, showing that Type As indeed successfully combine high performance and speed (Ben-Zur \& Wardi, 1994; Bermúdez et al., 1990; Pérez-Garcia \& Sanjuán, 1996). As mentioned before, Type As ignore feelings like fatigue and show extreme ambition and persistence to reach achievements as quickly as possible (Matthews, 1982). This can lead to high impatience of Type As and poor performance in tasks that need patience and slow work (Glass, 1980; Matthews, 1982).

In conclusion, Type A personality is a multiplex construct of distinctive cognitive and behavioral patterns, greatly dependent on the measurement used to assess it.

\section{Interaction of Type A Personality, Time Pressure, and Ethical Decision-Making}

The study of Rayburn and Rayburn (1996) was one of the few studies to directly examine the relationship between Type-A personality and ethical decision-making. Indeed, the authors found evidence supporting their hypothesis, as Type Bs were more likely to agree to unethical statements like "If a friend of mine has a computer software program that I want, it's OK for me to copy and use it” (Rayburn \& Rayburn, 1996: p. 1216). Following Rayburn and Rayburn (1996), the current study tries to contribute further research to this topic. The main reason for the scarcity of results lies in the aforementioned problems with inconsistencies resulting from the differing measurements of Type A personality. Nevertheless, we propose that research on Type A personality can be profitable.

The results of several studies indicate, albeit indirectly, that Type A personality could indeed elicit higher morality and ethical standards in decision-making. Type As always strive to maintain their self-esteem while setting high standards of performance (Grimm \& Yarnold, 1984; Pérez-Garcia \& Sanjuán, 1996; Strube \& Werner, 1985). It is therefore proposed that Type As display a high self-esteem regarding their own competency and act with the highest possible performance. Furthermore, many studies prove that Type As focus on the most relevant cues when making decisions (Ben-Zur \& Wardi, 1994; Bermúdez et al., 1990; Rayburn \& Rayburn, 1996). The perception of relevant cues is crucial in the ethical decision-making process, especially regarding moral awareness and judgement 
(Jones, 1991). The combination of high-performance standards, protection of self-esteem and perception of task-relevant cues leads-in line with Rayburn and Rayburn (1996) - to the proposal that Type As will show a heightened preference for morality in all components of Rest's (1986) model of ethical decisionmaking. Thus, we hypothesize:

1) Under standard conditions, Type $A$ individuals will be more ethical than Type B individuals regarding their moral awareness, moral judgement, moral intention and to their moral behavior.

Moreover, many studies prove that Type As show high performance in tasks that need immediate action and when put under time pressure (Ben-Zur \& Wardi, 1994; Matthews, 1982; Pérez-Garcia \& Sanjuán, 1996). The study of BenZur and Wardi (1994) as well as Pérez-Garcia and Sanjuán (1996) underlined that Type As can uphold their high level of performance while under time constraints, while Type Bs showed decreased performance. As Ben-Zur and Wardi (1994) put it, Type As "[...] take decisions rapidly but also wisely [...]" (p. 331). It is therefore proposed that Type As will maintain high preference for morality on all four components, while Type Bs ethical decision-making will be affected negatively by time pressure. Following, we hypothesize:

2) Under time pressure, Type B individuals, but not Type A individuals, will be less ethical regarding their moral awareness, moral judgement, moral intention and to their moral behavior.

\section{Present Study}

The aim of the present study was to take up and advance the investigation on Type A personality, ethical decision-making, and especially ethical decisionmaking under time pressure. Specifically, the ethical orientation of Type As, and the differences of ethical decision-making between Type As and Type Bs under time pressure were examined. Consequently, personality type and time pressure emerged as independent variables and influence the dependent variable of ethical decision-making.

\section{Method}

We conducted an experiment with a $2 \times 2$ between-subject design to explore the relationship between different types of personality (Type A versus B) and time pressure (No Time Pressure and Time Pressure) on the ethical decision-making process. For this reason, this study intended to explore differences between Type As and Type Bs in regard to their ethical decision-making, while putting approximately half of the subjects under time pressure.

\section{Participants}

The sample consists of $N=168$ subjects (111 women, 56 men and one person who did not specify) with a mean age of $M=22.98$ years ( $S D=3.9)$. We chose to recruit subjects with a comparable educational background, namely German- 
speaking students, to avoid unwanted effects on ethical decision-making. To provide high generalizability, our sample consists of students from over 20 different study programs, including psychology, accounting, medicine, jurisprudence, engineering, education, and from universities all over Germany. $N=91$ (54.2\%) subjects studied a form of psychology. Most participating students were native German speakers to ensure that the material, being presented in German, was thoroughly understood.

\section{Materials}

We conducted the experiment as an online survey. Therefore, in the current study all material was presented digitally and in German language.

\section{Student Jenkins Activity Survey (SJAS)}

The SJAS was employed in the present study to identify Type A and Type B personalities, especially in student samples. The original Jenkins Activity Survey (JAS) was developed by Jenkins et al. in 1967, while aiming to economize the examination of the relationship between the coronary-prone behavior pattern, also called Type A behavior pattern, and coronary heart disease (CHD). Its goal was to develop "[...] a rapid objective measurement technique [...]" superseding the uneconomic structured interviews previously used to differentiate between Type A and Type B personalities (Jenkins et al., 1967: p. 2). A number of studies report agreements between the interview and the JAS between $63 \%$ and $73 \%$ (Jenkins et al., 1967, 1971; Matthews et al., 1982). The original JAS was a selfadministered paper-and-pencil questionnaire, consisting of 54 items and a unit scoring system was used to discriminate between Type As and Type Bs (Jenkins et al., 1967). Zyzanski and Jenkins (1970) then discovered the three underlying factors of Hard Driving, Job Involvement, and Speed and Impatience, showing that Type A personality is better represented as a collection of dissimilar traits.

Krantz et al. (1974) were the first to modify the JAS to fit a college-student population. The modified version of the JAS was dubbed Student Version of the $J A S$ by Glass in 1977 and consists of 21 items. Regarding the scoring, a unit weighting procedure is used to discriminate between Type As and Type Bs (Glass, 1977). The superiority of a unit-weighting procedure was supported by a study of Jenkins et al. (1971). Responses representing Type A personality are scored with 1, while Type B responses are scored with 0 points, leading to a maximum score of 21 (Glass, 1977). The items typically include two to four answer options, of which one or two represent Type A responses (Glass, 1977), e.g., for the question "Do you ever set deadlines or quotas in courses or other things?" possible answers were "yes" (Type A) and "no" (Type B).

Following, a median-split is executed, whereby subjects scoring below the median are classified as Type Bs and subjects scoring above the median are classified as Type As (Glass, 1977).

Regarding the psychometric criteria of the SJAS, reliability was most often 
examined. Yarnold et al. (1986) first reported moderate internal consistencies ranging from $\alpha=.40$ to $\alpha=.72$, depending on sex and ethnicity, and high retest reliabilities of .70 to .96 , depending on the period of retesting. In accordance with these criteria, Bishop et al. (1989) also reported moderate internal consistencies, namely a Cronbach's alpha of .64 and high test-retest reliabilities, ranging from .67 to .74 .

Matthews (1982) states that the measurement of Type A yields many problems and that the most common measures all assess differing aspects of the broad spectrum of Type A personality. Therefore, it is important to stress what the JAS and SJAS do not measure sufficiently: hostility, aggressiveness and clinically relevant factors related to CHD (Matthews, 1982). According to Matthews (1982), Type As classified by the JAS “[...] sense time passing rapidly, work quickly, persist in the face of fatigue or the possibility of failure, and ignore distractions that can interfere with a good performance." (p. 304). In the current study we try to examine the relation between Type A personality and time pressure, and by that the SJAS is the most fitting measurement of Type A personality (Matthews, 1982). Moreover, the SJAS is the most popular method to assess Type A personality in student samples (Bishop et al., 1989, Bryant \& Yarnold, 1995).

Regarding the present study, we translated the SJAS in German and one item was altered. From the original item "Do you maintain a regular study schedule during vacations such as Thanksgiving, Christmas, and Easter?" (Glass, 1977: pp. 178-179), the holiday of Thanksgiving was excluded because it is not celebrated in Germany and therefore irrelevant for a German sample. In the present study, Cronbach's alpha for the SJAS was $a=.62$, indicating a questionable internal consistency of the scale. All results regarding personality type must be interpreted with caution. The internal consistencies of the subcomponents of HardDriving/Competitive $(\alpha=.58)$ and Speed/Impatience $(\alpha=.37)$ did not allow further analysis of these components.

\section{Vignette}

The expansive review on ethical literature of O'Fallon and Butterfield (2005) proved the common use of ethical scenarios in examination of ethical decisionmaking, showing that $55 \%$ of the examined studies used a scenario approach. A row of studies explain the adequacy of vignette use by underlining that it enables the observation of judgement and behavior that cannot be observed under real conditions for ethical reasons (Aguinis \& Bradley, 2014; Alleyne et al., 2018; Latan et al., 2019). Especially unethical behavior is hard to assess or observe in experimental settings and ethical reasons do not allow for manipulation to elicit unethical behavior (Alleyne et al., 2018; Latan et al., 2019). Several studies support the improved quality of examination by using a scenario approach (O'Fallon \& Butterfield, 2005; Singhapakdi et al., 1996). Furthermore, it is surmised that vignettes combine the strengths of classical experiments and survey methodology to increase the internal and external validity at the same time (Aguinis \& 
Bradley, 2014; Atzmüller \& Steiner, 2010). Based on the thorough analysis of scenarios and following the recommendations of Aguinis and Bradley (2014), we chose to use the scenario "Donations for Profit" by Eric Knox (Buchholtz \& Carol, 2012: p. 21). We modified the scenario to match the examined sample and study design. Originally, the scenario was addressed to managers, therefore not being adequate for a student sample. To enable sufficient immersion and relatability, we reformulated the vignette to address students and not professionals. The importance of immersion is supported by the guide of Aguinis and Bradley (2014). Furthermore, Ferris and colleagues (1997) stressed that the respondent needs to feel as if he or she is actually in that situation, thereby increasing the validity of the vignette. To avoid uncontrolled contextual influences and to increase the economy of the study, we chose to only use one scenario in this study. According to Aguinis and Bradley (2014), when using only one scenario and a between-subject design (both is the case in the present study), it is important to provide extensive information and context to ensure that realistic judgements of the participants are reflected correctly. Again, closely following the recommendation, we modified the vignette and added further background information to ensure sufficient contextual information. In conclusion, we complied with the most pertinent recommendations of scientific literature regarding the experimental vignette methodology and therefore provided sufficient psychometric criteria.

In the vignette, the reader is asked to put oneself in the position of a student who works at a golf club. In the weeks to come, a golf tournament for children is scheduled. With much effort, the reader collected $3000 €$ of local shopkeepers, who donated the money to buy awards for the participating children. Unexpectedly, the manager of the golf club asks to use only half of the money to buy awards for the children, whereas the other half should be entered as profit of the golf club. The manager emphasizes the poor economic situation of the club and that the money is needed urgently.

After reading the vignette, participants were asked to answer questions regarding different ethical aspects in regard to the vignette, which are described below.

\section{Questionnaire on Ethical Decision-Making}

We created our questionnaire based on the four components of Rest's (1986) model of ethical decision-making, thereby using the most prevalent model for ethical decision-making. The items measure the different components of the model: Moral awareness, moral judgment, moral intention and moral behavior.

\subsection{Moral Awareness}

Based on Singhapakdi et al. (1996), we posed a single item to ensure that the presented scenario is indeed perceived as a moral dilemma by our participants. Only then can it be assured that an ethical decision-making process will start (Hunt \& Vitell, 1986; Jones, 1991). 
The item reads "The depicted situation displays an ethical problem." (p. 16) and is rated on a 7-point Likert scale of agreement ranging from $1=$ strongly disagree to $7=$ strongly agree. By that, it is ensured that the assessed scenario is perceived as a moral issue, setting off the ethical decision-making process (Jones, 1991).

\subsection{Moral Judgement}

The second component of Rest's (1986) model, namely moral judgement, was assessed by following Marquardt's (2010) recommendation on using a four-item scale containing two utilitarian and two deontological items. For each ethical orientation, one item targeted the ethical option, while the second item targeted the unethical option. First, the utilitarian items read "Taking all consequences into account, spending $3000 €$ on the purchase of prizes/ entering $1500 €$ as profit is in the best interests of those individuals involved". Second, the deontological items read "By spending $3000 €$ on the purchase of prizes/ entering $1500 €$ as prof$i t$, you incorporate your obligations to others". The italicized parts indicate the ethical and unethical option. In accordance with moral awareness, all items were again rated on a 7 -point Likert scale ranging from $1=$ strongly disagree to $7=$ strongly agree. To calculate a mean of moral judgement, items 2 and 4 must therefore be calculated with reversed polarity. In the present study, reliability of the four-item scale was $\alpha=.54$, and therefore questionable. After further examination, the fourth item was excluded from further analysis, leading to an acceptable internal consistency of $\alpha=.77$. Reasons and implications will be discussed.

\subsection{Moral Intention}

When assessing the third component, moral intention, we again adopted the proposal of Marquardt (2010). The examination of moral intention therefore consisted of one bipolar item asking the participants to express their inclination for one of two behavioral options ("What do you tend to do?"). Again, a 7-point Likert scale was used, ranging from $1=$ Grant $1500 €$ as profit to $7=$ Purchase prizes for $3000 €$. The assessment of moral intention is in accordance with Rest (1986) and Jones (1991) and important to show possible discrepancies with the final decision.

\subsection{Moral Behavior}

For the fourth component, moral behavior, we again adopted the study of Marquardt (2010) as a model. Following, in the present study one nominal item was posed, and participants needed to choose either the ethical or the unethical option ("For which option do you decide?"). The options read "Grant $1500 €$ as profit" and "Purchase prizes for $3000 €$ ". Correspondingly, the participants acted as moral agents and had to execute a decision (Jones, 1991; Rest, 1986). 


\subsection{Design and Procedure}

The combination of a dichotomous personality Type (Type A or B) and a dichotomous time condition (No Time Pressure and Time Pressure) elicited a $2 \times$ 2 between-subject design. In the current study, a random assignation was not possible due to the usage of an online survey. Because inter alia student groups consisting of only psychology students were used, the assignation to time condition lacked proper randomization. Limitations will be discussed.

On the first page of the survey, the privacy policy in accordance with European law was displayed and all participants confirmed consent to the anonymized use of their data for statistical analysis. The second page included the assessment of age, sex, and study program. In the next step, the SJAS was assessed, and participants needed to complete all 21 items. Depending on the version of the survey, the next page either displayed the vignette without time pressure or the vignette and the questionnaire on ethical decision-making were presented under time pressure. In the time pressure condition, a headline read that the participants had 4 minutes to read the vignette and complete the questionnaire and they were further told that they should hurry. No time restrictions existed for the other group.

\section{Results}

\subsection{Manipulation Checks}

We ran several manipulation checks to examine whether the demographic variables of sex, study program, and age as well as the participants' personality were independent of the conditions of Time Pressure and No Time Pressure. The results of the chi-square test for personality type (i.e., Type A or Type B) yielded no significant influences of personality type on time condition $\left(\chi^{2}(1, N=\right.$ $168)=.177, p=.67, \varphi=.03)$. Moreover, the chi-square test of sex on time condition $\left(\chi^{2}(2, N=168)=4.604, p=.10, \varphi=.17\right)$ and the binary logistic regression of age on time condition $(B=.08, p=.15)$ showed no significant influences of sex and age on the allocation to time condition. Surprisingly, the chi-square test of study program (coded as $1=$ psychology student and $2=$ not psychology student) on time condition revealed significant influences of study program on the allocation to time condition $\left(\chi^{2}(1, N=168)=9.364, p=.002, \varphi=.24\right)$. Therefore, significantly more psychology students were allocated to the No Time Pressure condition. The implications of this manipulation will be discussed.

The next step involved checking if the vignette was recognized as a moral issue. According to Jones (1991), the recognition of a moral issue is crucial for triggering the ethical decision-making process. Following Singhapakdi et al. (1996), we posed a direct item asking the participant if the scenario represents a moral issue. The mean response of $M=6.32(S D=1.12)$ on a 7-point Likert scale was significantly higher than the scale's neutral level of $4(t(167)=26.791$, $p<.001)$. Consequently, we concluded that the vignette was indeed perceived as a moral issue, setting off the participants' ethical decision-making process and 
confirming the participants' moral awareness.

\subsection{Descriptive Statistics, Distributions, and Intercorrelation of Variables}

Analysis of Means and Standard Deviations showed that subjects scored on a range from 0 to 15 on the SJAS $(M=8.14, S D=3.14)$. Subsequently, we conducted a median-split to assign participants to the categories of Type A and Type B personality, thereby following the method recommended by Glass (1977). Participants, who scored 8 or less on the SJAS were classified as individuals with Type B personality, whereas subjects who scored 9 or more on the SJAS were classified as individuals with Type A personality. Following this classification, our sample included 76 subjects with Type A personality and 92 subjects with Type B personality. Frequency distribution of the SJAS scores can be seen in Figure 1.

Following, mean, standard deviations, and intercorrelations of the ethical variables were analyzed. Participants' moral judgement scores indicated that most participants appraised the spending of money on prizes as the morally appropriate choice $(M=5.65, S D=1.18)$. As noted earlier, the fourth item was excluded from further analysis of overall moral judgement due to low internal consistency. Nevertheless we compared the scales for all utilitarian judgement $(M=5.35$, $S D=1.46)$ and deontological judgement $(M=4.98, S D=1.19)$ and revealed a significant difference between the two means $(t(167)=3.045, p=.003, d=.24)$. The item expressing a utilitarian ethic produced significantly higher moral judgement than the one formulated in a deontological ethic. Again, because of the low internal consistency of the deontological scale, results must be interpreted with great caution. In accordance with moral awareness and judgement, the means for moral intention also stressed the preference for the moral choice $(M=5.47$, $S D=1.56)$. Shapiro-Wilk-tests of normality for the three variables were significant, and hence, all three variables are not normally distributed. Results distributions were leptokurtic and negatively skewed, giving emphasis to the overall preference for ethical decisions. Regarding moral behavior, 78.6\%, in other words 132 out of 166 subjects, chose the moral option. The overall strong preference

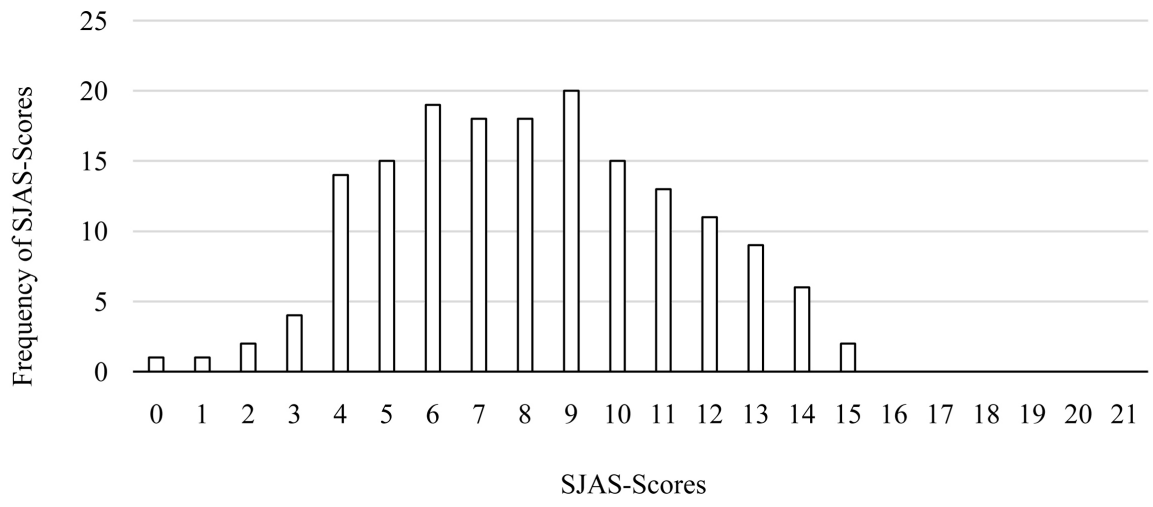

Figure 1. Frequency distributions of participants' scores on the SJAS. 
for the moral option observed in moral awareness, judgement and intention is therefore not incontestably reflected in the moral behavior itself.

In the following step, intercorrelations between personality, time condition and the ethical decision-making variables were investigated. Results yielded no significant correlations of personality with any of the other examined variables. In general, having Type A personality showed small positive correlations with moral judgement, intention and behavior, without reaching significance. The manipulation of the time condition resulted in small, negative correlations of time pressure with moral judgement and intention, whilst failing to reach significance as well.

Interestingly, the negative correlation of time pressure with moral behavior is significant, indicating that time pressure is associated with unethical behavior $(r=-.16)$. The intercorrelations of moral awareness, judgement, intention, and behavior showed strong overall correlations for the variables. The results revealed small significant correlations of moral awareness with the three moral judgement scales, intention, as well as behavior. The intercorrelations between moral judgement, intention and behavior revealed medium to high significant correlations between the three steps of the ethical decision-making process (see Table 1).

\subsection{Effects on Ethical Decision-Making}

In the next step, ANOVAs, regression analyses and a loglinear analysis were conducted to explore the interaction between demographics, subject's personality type and the components of the ethical decision-making process. Because of the questionable reliability of the measures used to assess personality type and the absence of normal distribution in all ethical components, most results must be interpreted with caution.

Table 1. Means, standard deviations and inter-correlations of variables.

\begin{tabular}{|c|c|c|c|c|c|c|c|c|c|c|}
\hline Variable & $M$ & $S D$ & 1 & 2 & 3 & 4 & 5 & 6 & 7 & 8 \\
\hline 1) Personality Type & - & - & - & & & & & & & \\
\hline 2) Time Pressure & - & - & .03 & - & & & & & & \\
\hline 3) Moral Awareness & 6.32 & 1.12 & .00 & -.03 & - & & & & & \\
\hline 4) Moral Judgement & 5.65 & 1.18 & .08 & -.12 & $.27^{\star *}$ & - & & & & \\
\hline $\begin{array}{l}\text { 5) Judgement } \\
\text { Utilitarian }\end{array}$ & 5.35 & 1.46 & .09 & -.07 & $.24^{* *}$ & - & - & & & \\
\hline $\begin{array}{l}\text { 6) Judgement } \\
\text { Deontological }\end{array}$ & 4.98 & 1.19 & .05 & $.42^{\star *}$ & $.18^{*}$ & - & $.31^{\star *}$ & - & & \\
\hline 7) Moral Intention & 5.47 & 1.56 & .11 & -.09 & $.25^{\star *}$ & $.80^{\star *}$ & $.78^{\star *}$ & $.35^{\star *}$ & - & \\
\hline 8) Moral Behavior & - & - & .07 & $-.16^{*}$ & $.16^{*}$ & $.62^{* *}$ & $.61^{* *}$ & $.26^{* *}$ & $.70^{\star *}$ & - \\
\hline
\end{tabular}

Note: Values regarding moral awareness, intent and the three judgment variables depend on a score range of $\min =1$ and $\max =7$, whereby higher values indicate higher levels of morality. Personality type (Type $\mathrm{B}=1$, Type $\mathrm{A}=2$ ) and moral behavior (immoral option $=1$, moral option $=2$ ) were scored on a dichotomous scale and therefore do not allow for the calculation of a mean value. Time pressure was coded with No Time Pressure $=1$ and Time Pressure $=2 .{ }^{*} p<.05 .{ }^{* *} p<.01$. 
ANOVAs on the influences of sex, and study program, and a binary logistic regression on the influences of age on the ethical components yielded no significant results. However, effects of age on moral judgement $(B=.04, t(166)=$ $1.911, p=.06)$ and intention $(B=.06, t(166)=1.829, p=.07)$ were marginally significant, indicating a weak association between age and ethical decisionmaking. Age explained only $2 \%$ of the collective variance in moral judgement and intention.

Further, the interactions between personality type, time pressure and the four components of ethical decision-making were examined in the subsequent step.

Moral awareness. The results of the first ANOVA of effects on moral awareness can be seen in Table 2. Results yielded no significant main effects of personality type or time pressure and furthermore the interaction yielded no significant effects either (all $F_{\mathrm{s}}<.2$ ). Homogeneity of variances was confirmed by a non-significant Levene-Test, $F(3,164)=.112, p=.95$.

To further analyze the direction of the interactions, we employed Post-Hoc tests according to Gabriel. When comparing the moral awareness of Type Bs ( $M=$ $6.35, S D=1.25)$ and Type As $(M=6.37, S D=1.15)$ without time pressure. Unsurprisingly, results indicated no difference between the two groups, $(-0.2,95 \%$ CI $[-.67, .63]), p>.999$. Correspondingly, the difference between Type Bs $(M=$ $6.3, S D=.96)$ and Type As $(M=6.26, S D=1.13)$ under time pressure produced no significant difference, $(.04,95 \%$-CI $[-.63, .71]), p>.999$. When comparing the difference of time conditions within personality type, we found a small, nonsignificant effect for Type As, $(.11,95 \%$-CI $[-.59, .80]), p>.999$, indicating a weak association between time pressure and impaired moral awareness for Type As. Time condition resulted in no significant effect on the moral awareness of Type Bs, (.04, 95\%-CI [-.59, .67]), $p>.999$.

Moral judgement. Subsequently, moral judgement was examined. Again, homogeneity of variances was confirmed by a non-significant Levene-test, $F(3,164)$ $=.657, p=.58$. Akin to moral awareness, an ANOVA yielded no significant main effects of personality type or time pressure and no significant effect of the interaction between both factors on moral judgement.

Post-Hoc-tests according to Gabriel showed that under no time pressure, Type Bs $(M=5.72, S D=1.05)$ exhibited a non-significant (slightly lower) moral judgement than Type As $(M=5.87, S D=1.12)$. The effect-size was small and failed to reach significance, $(-.15,95 \%$-CI $[-.82, .53]), p>.999$. When put under

Table 2. ANOVA of effects on moral awareness.

\begin{tabular}{ccccc}
\hline & $d f$ & $F$ & $p$ & $\eta_{\text {partial }}^{2}$ \\
\hline Corrected Model & 3 & .07 & .98 & .001 \\
Type A/B & 1 & .003 & .96 & $<.001$ \\
Time Pressure & 1 & .18 & .67 & .001 \\
Type A/B ${ }^{\star}$ Time Pressure & 1 & .03 & .86 & $<.001$ \\
\hline
\end{tabular}


time constraints, Type As showed reduced (but non-significant) moral judgement, $(-.24,95 \%$-CI $[-.95, .48]), p=.94$. In accordance to that, the same effect was observed for Type Bs, who exhibited reduced moral judgement when put under time constraints, $(-.33,95 \%$-CI $[-.98, .33]), p=.71$. Lastly, the moral judgements of Type As and Type Bs under time pressure were compared and resulted in lower moral judgement of Type Bs, (-.24, 95\%-CI [-.93, .46]), $p=.93$. Hence, Type As displayed non-significantly higher moral judgement scores than Type Bs and a non-significant reduction of moral judgement under time pressure was reported for both personality types.

Moral intention. In accordance with the ethical decision-making process, moral intention was examined in the subsequent step. Again, the homogeneity of variances was confirmed by a non-significant Levene-test, $F(3,164)=.876, p=.46$. Analogous to the ANOVAs on moral awareness and judgement, the ANOVA of effects on moral intention yielded neither significant main effects, nor a significant interaction of personality type and time pressure.

Post-Hoc-tests according to Gabriel again revealed a non-significant slightly lower moral intention of Type Bs $(M=5.51, S D=1.37)$ compared to Type As $(M=5.71, S D=1.51)$ when under no time pressure, $(-.2,95 \%$-CI $[-1.09, .69])$, $p>$.999. When put under time pressure, Type As exhibited a slightly lower moral intention, $(-.11,95 \%$-CI $[-1.06, .85]), p>.999$. The effect of time pressure on moral intention of Type Bs was larger, (-.42, 95\%-CI [-1.28, .45]), $p=.36$. Hence, when put under time pressure, the moral intention of Type Bs was decreased. Finally, when comparing both personality types under time pressure, the decreased moral intention of Type Bs was directly reflected, (-.51, 95\%-CI $[-1.43, .41]), p=.59$. Consequently, Type As again exhibited a non-significantly higher moral intention than Type Bs, and the difference was expanded when put under time pressure. It is important to note that the standard deviations, especially for moral intention, but also for moral awareness and judgement, were rather large and therefore all results must again be interpreted with caution.

Moral behavior. In a final step, moral behavior was examined. Due to a dichotomous answer format (Purchase prize for $1500 \$$ versus Purchase prize for $3000 \$$ ), we executed a loglinear analysis to examine the influences of personality type and time pressure on moral behavior. Results are depicted in Figure 2. The three-way loglinear analysis yielded a final model that retained the time-pressure $^{*}$ moral-behavior interaction as the model with the greatest plausibility. The likelihood ratio of this model was $\chi^{2}(4)=2.922, p=.57$, and it therefore represents an acceptable fit to the observed data. The interaction of time-pressure*moralbehavior was significant, $\chi^{2}(1)=4.544, p=.03$. This significant interaction indicates that the frequency of moral behavior was different between the two time conditions, indicating more moral behavior (Purchase prize for $3000 \$$ ) within participants without time pressure. The models of personality ${ }^{\star}$ time-pressure ${ }^{\star}$ moral-behavior and personality ${ }^{\star}$ moral-behavior were rejected. The odds of taking the immoral option were 2.26 times higher under time pressure. 


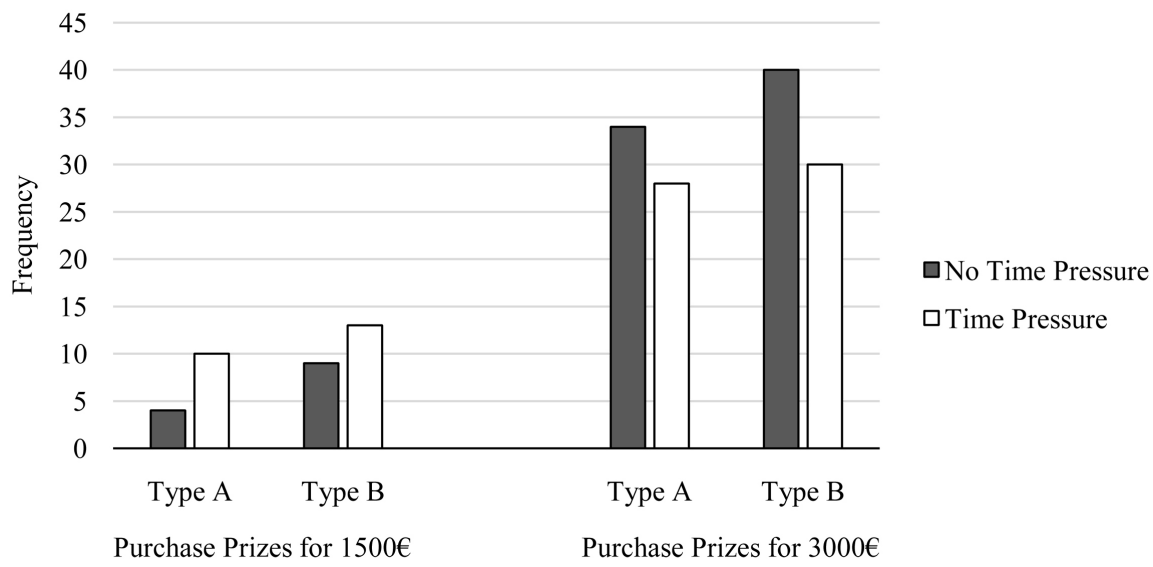

Figure 2. Frequency of moral behavior.

\section{Discussion}

The present study aimed to advance the investigation of the interaction between Type A personality, time pressure and four components of ethical decision-making (Rest, 1986). Regarding personality type, the results showed no significant correlations with any of the other examined variables. Closer examination indicated a higher preference of Type As in comparison to Type Bs regarding moral orientation. The correlation analyses and ANOVAs failed to produce significant associations between personality type and ethical decision-making, and therefore all hypotheses had to be rejected. Following results revealed a significant negative association between time pressure and moral behavior. Generally, the propensity of students to take the immoral option was rather high in the present study. The present study indicates possible differences between Type As and Bs and further advances the research regarding time pressure and ethical decision-making. Additionally, the high frequency of immoral decisions stresses the notion that unethical behavior is quite common and needs to be prevented. The psychometric criteria of the measures employed to assess personality and ethical decision-making revealed questionable internal consistencies. All results and implications will be discussed hereinafter.

\section{Discussion of Empirical Findings}

Firstly, following the four-component model of Rest (1986), results regarding moral awareness will be scrutinized. Analysis of the intercorrelations revealed no significant associations between moral awareness and personality type or time condition. Post-Hoc tests according to Gabriel supported the notion that moral awareness scores did not differ for Type As or Type Bs, and that time pressure had no significant effect on moral awareness. We assume that the moral issue of the scenario used to assess ethical decision-making was rather obvious, thereby resulting in high salience. Due to the high salience of the moral issue, the propensity of participants to perceive the scenario as moral was extraordinarily high. Additionally, the vignette produced a ceiling effect in the present study, 
therefore potentially diminishing differences between personality type and time condition. Accordingly, the results do not confirm our hypotheses. Nevertheless, the results stand in line with Jones (1991) who argued that high salience of ethical cues in a situation will lead to moral intensity of the situation, thereby further leading to frequent recognition of the situation as moral.

Regarding the other ethical components, moral awareness showed significant but weak correlations with judgement, intention, and behavior. These correlations support Rest's (1986) model, showing that the four components of ethical decision-making are related, however distinct steps. The rather small correlation between awareness and the three following components are further in line with the results of Chan and Leung (2006), showing that awareness does not necessarily predict moral reasoning sufficiently.

In the next step, the results regarding moral judgement and intention will be examined. Again, the intercorrelation analysis failed to produce significant associations of moral judgement with personality type or time condition. These results were further supported by an ANOVA and following Post-Hoc tests. Type As showed impaired moral judgement under time pressure, and this effect was even bigger for Type Bs, but both effects failed to reach significance. Furthermore, results indicate a non-significant trend that Type As exhibited higher degrees of moral judgement than Type Bs under no time pressure as well as under time pressure. Again, it is important to note that due to large standard deviations and low internal consistencies, both effects failed to reach significance. Accordingly, the results do not confirm our hypotheses. Nevertheless, these results indicate that Type As might indeed elicit slightly higher moral reasoning. The results for moral judgement and intention displayed high resemblance. Again, intercorrelations, as well as the ANOVA and Post-Hoc tests, failed to evoke any significant findings regarding differences in moral intention. In accordance with moral judgement, Type As exhibited higher moral intention than Type Bs. Being under time pressure resulted only in slight differences of moral intention in Type As while the differences for Type B were larger. The comparison of both personalities under time pressure underlined the impaired moral intention of Type Bs under time pressure. Again, all results failed to reach significance. Accordingly, the results do not confirm our hypotheses. Results of higher moral judgement and intention of Type As would be in line with the investigation of Rayburn and Rayburn (1996), showing that Type As tend to be more ethically oriented. On the other hand, factors like self-serving interests could also explain the non-significant difference between Type As and Bs. As Rest (1986) stressed, self-serving interests of individuals can contradict their ethical reasoning. It is therefore possible to assume that Type As identified themselves as part of the Golf Club, and therefore strived to achieve high performance in their job, diminishing the difference to Type Bs. We suppose that the questionable psychometric criteria of our measurements lead to impaired significance of the results. Due to the high standard deviations and the absence of significant findings, we refrain from fur- 
ther interpreting the effects. Implications will be discussed. Again, in accordance with the model of Rest (1986), judgement showed moderate correlations with the components of intention and behavior. The study of Musbah et al. (2016) further examined the function of moral judgement and showed that moral judgement and moral intention are indeed associated, and that the relationship between moral awareness and intention is strongly mediated by moral judgement.

In a final step, the fourth component of ethical decision-making, namely moral behavior, was scrutinized. A three-way loglinear analysis was executed and revealed a significant association between time pressure and unethical behavior. This negative association is supported by the significant negative correlation of time pressure and moral behavior in the analysis of intercorrelations. The models of personality ${ }^{\star}$ time-pressure ${ }^{\star}$ moral-behavior, and personality ${ }^{\star}$ moral-behavior failed to reach significance and were therefore rejected. Accordingly, the results do not confirm our hypotheses. The negative association between time pressure and moral behavior stands in line with a great number of studies, showing that time pressure indeed elicits unethical behavior (Andiappan \& Dufour, 2016; Belle \& Cantarelli, 2017; Koh et al., 2011, 2018). Nevertheless, it is of high importance to not assume that time pressure axiomatically impairs ethical decision-making. Investigations of Dror et al. (1999) as well as Moberg (2000) showed that time pressure effects decision-making in the shape of an inverted $U$. These results are in correspondence with the differing results in the studies we examined regarding decision-making under time pressure, showing that moderate time pressure can lead to improved performance. Moberg (2000) adds that factors like accessibility of ethical standards, salience of alternatives and cognitive effort are crucial to explain interactions between time pressure and ethical decision-making.

The absence of differences in moral behavior between Type As and Type Bs might again be explained by self-serving choices. As the study of Andiappan and Dufour (2016) revealed, individuals take more self-serving choices when put under time constraints. The investigation of Strube et al. (1985) further revealed that Type As stick to their strong belief in own competences, even when the situation is unclear. We can therefore only assume that factors like a self-serving orientation of Type As as well as their strong belief in own competences, even against contextual information, might diminish the differences between Type As and Type Bs. Nonetheless, we must stress that no proficient interpretation is possible based on the psychometric criteria of the present study.

Following our results, our hypotheses have to be rejected. The results indicate no significant and explicit differences between Type A and B individuals regarding their moral awareness, moral judgement, moral intention and to their moral behavior, regardless of existing time-pressure (versus not). Nevertheless, results indicate relationships between time-pressure and moral behavior.

\section{Strength and Implications}

The present study presents several theoretical and practical implications. In the 
recent decades, there has been a significant decline in research regarding Type A personality. Rayburn and Rayburn (1996) were the last to examine the relationship between Type A personality and ethical behavior. Furthermore, Ben-Zur and Wardi (1994) conducted the last expansive study to investigate the relationship between Type A personality and decision-making under time pressure.

Regarding the methodology, the examination of ethical decision-making was in line with Rest's (1986) model. Furthermore, the design of the vignette was closely oriented to the best practice recommendations of Aguinis and Bradley (2014), and therefore, produced sufficient psychometric criteria. Nonetheless, the vignette resulted in limitations that will be discussed in the next part.

With respect to the models of ethical decision-making of Rest (1986) and Jones (1991), the present study further supports the relationship between the four components. The low correlations of moral awareness with moral judgement, intention, and behavior thereby stand in line with their idea that the steps are conceptually distinct. We suppose that factors like self-serving motives, affect, moral intensity, and schemes of justice might influence the four steps, thereby explaining discrepancies between them (Jones, 1991; Rest, 1986). It would therefore be of high interest to include the measure of such factors in future studies examining ethical decision-making.

The present study failed to produce significant effects of personality, while indicating a preference of Type As for moral judgement and intention. Several studies support the superior performance of Type As (e.g., Ben-Zur \& Wardi, 1994; Bermúdez et al., 1990; Pérez-Garcia \& Sanjuán, 1996). In modern day-today life, most individuals deal with numerous ethical decisions and high time pressure daily. Future studies should therefore strive to further examine the role of Type A personality in this complex interaction. Implications on how to examine the role of Type A personality better will be elucidated in the limitations.

The results regarding the propensity to act unethically further underline the high relevance proposed in our introduction. In the current study, 36 out of 166 participants, in other words $21.7 \%$, chose the immoral option. The high propensity to act unethically therefore clearly supports the claim of Sims (1992) that "Unfortunately, unethical (organizational) practices are embarrassingly commonplace" (p. 507). One reason for the high frequency of immoral behavior might be explained by the study of Selart and Johansen (2010) who showed that the absence of rewards is highly associated with unethical behavior. In the vignette that we employed, the immoral behavior will not be noticed and therefore an individual has no clear incentives to act morally. In accordance with the model of moral intensity of Jones (1991), magnitude of consequences and social consensus were rather low in the employed scenario and therefore immoral behavior might be exhibited more frequently. Our results stress the notion that unethical behavior is rather common and needs to be prevented. A number of studies show that trainings regarding ethical and emotional education can lead to higher frequency of ethical reasoning and behavior (Chan \& Leung, 2006; Jeong et al., 
2020). Furthermore, several studies support this notion by proving associations between education and factors like recognition of moral issues or ethical reasoning (O'Fallon \& Butterfield, 2005; Sweeney \& Costello, 2009). If organizations want to curtail their employees' propensity to reason and act unethically, it is therefore advisable to focus on education and trainings regarding these topics. Future studies should further examine the relationship between type of training or education and ethical decision-making to develop proficient models of training.

\section{Limitations}

First, our method of acquiring participants lead to manipulation effects between study program and time condition. In the present study, psychology students were significantly more often assigned to the condition without time pressure. Therefore, the absence of proper randomization might have produced effects that we are not aware of. Results regarding study program and time condition must therefore be interpreted with this manipulation in mind. The study of Chan and Leung (2006) indeed showed that the study program might affect factors such as ethicality of students.

As already mentioned, the vignette we employed might have been too obvious and therefore lead to ceiling effects in the moral awareness of the participants. Future studies should therefore employ vignettes which are more complex and lead to a better distinction between subjects.

Finally, the present assessment of Type A personality must be reviewed critically. The SJAS revealed questionable internal consistencies of $\alpha=.62$ in the present study. The internal consistencies of the subcomponents of Hard-Driving/Competitive $(\alpha=.58)$ and Speed/Impatience $(\alpha=.37)$ were even lower and did not allow for further analysis. Following, we had to assess Type A personality as a global construct, against the recommendations of the pertinent scientific literature (Matthews, 1982). The low correlations with the other examined variables are therefore not surprising and can be explained by the questionable psychometric criteria of the SJAS. The problems of assessing Type A personality stand in line with many studies, showing that no clear construct and measurement for Type A personality have been developed (Matthews, 1982). As Matthews (1982) put it: “This psychometric imprecision renders interpretation of findings somewhat ambiguous" (p. 315). The absence of clear behavioral characteristics of Type A across the different measures lead to problems in interpretation, making it unclear if parts of the variance are caused by the construct itself or not (Matthews, 1982). Further following Matthews (1982), it becomes obvious that the methodology employed in the current study is suboptimal to assess Type A personality. According to her, situations that elicit clear differences between Type As and Bs “[...] (a) are moderately competitive; (b) are uncontrollable; (c) require endurance; (d) require slow, careful work; and (e) use a broad focus of attention." (Matthews, 1982: p. 317). We suppose that the em- 
ployed vignette fails to sufficiently cover all aforementioned situational characteristics. Furthermore, the more recent studies of Bryant and Yarnold (2014a, 2014b, 2014c) and Yarnold (2014) underline, how research regarding Type A personality can be optimized. In their studies, Bryant and Yarnold only used extreme Type As and Bs of big samples and employed tools of statistical analysis developed by themselves. The dubious psychometric criteria of the present study lead to the conclusion that our methodology is outdated and relied on legacy methods, making interpretation perilous by not covering the data sufficiently. The combination of questionable psychometric criteria and insufficient situational characteristics of the vignette lead us to underline our notion that our results regarding Type A personality cannot be interpreted proficiently. Future studies should therefore strive to clearly define the assessment of Type A personality, produce higher reliabilities and follow the recommendations of Matthews (1982) as well as the example of Bryant and Yarnold (2014a, 2014b, 2014c) to provide clear distinctions between Type As and Bs.

\section{Conclusion}

The current study aims to provide insights into personal and situational influencing factors of ethical decision-making in the work context. Therefore, we compared Type A versus Type B personalities regarding different ethical issues either under time restraints or without. Results reveal no significant differences in Type As versus Type Bs ethical decision-making in four different moral domains, namely moral awareness, moral judgement, moral intention, and moral behavior. Our hypothesis that Type A personalities could elicit higher morality and ethical standards in decision-making must therefore be rejected. The differentiation of the two types of personality (A versus B) in ethical decisions might need to be rethought. Also, innovative methods of measuring the two types might need to be determined. Future research should continue these thoughts and consider both issues in more depth. Our study could be used as a start-off point for new research in the field of Type A versus B personality, a research area that has not been paid a lot of attention to in the last years.

Interestingly, our results revealed significant negative associations between time pressure and (only) one moral domain, namely moral behavior, indicating more moral behavior within participants without time pressure. This is consistent with our hypothesis and previous findings. Additionally, this result adds to the existing literature by extending knowledge about the special domain of moral behavior under time pressure in the occupational context.

In conclusion, our results demonstrate interesting points in the area of ethical decision making under time pressure, whereas no connection to examined differences in personality occurred. Future research should continue to shed light on different personal as well as situational factors related to ethical decision making, time pressure and different types of personality. 


\section{Conflicts of Interest}

The authors declare no conflicts of interest regarding the publication of this paper.

\section{References}

Ackerman, D. S., \& Gross, B. L. (2003). Is Time Pressure All Bad? Measuring the Relationship between Free Time Availability and Student Performance and Perceptions. Marketing Education Review, 13, 21-32. https://doi.org/10.1080/10528008.2003.11488825

Aguinis, H., \& Bradley, K. J. (2014). Best Practice Recommendations for Designing and Implementing Experimental Vignette Methodology Studies. Organizational Research Methods, 17, 351-371. https://doi.org/10.1177\%2F1094428114547952

Ahituv, N., Igbaria, M., \& Sella, A. (1998). The Effects of Time Pressure and Completeness of Information on Decision Making. Journal of Management Information Systems, 15, 153-172. https://doi.org/10.1080/07421222.1998.11518212

Alleyne, P., Hudaib, M., \& Haniffa, R. (2018). The Moderating Role of Perceived Organisational Support in Breaking the Silence of Public Accountants. Journal of Business Ethics, 147, 509-527. https://doi.org/10.1007/s10551-015-2946-0

Andiappan, M., \& Dufour, L. (2016). Quick Decisions Tend to Reinforce Self-Interest Choices among MBA Students: The Direct and Moderating Effects of Temporal Constraint and Situational Factors in Ethical Decision Making. Canadian Journal of Administrative Sciences, 35, 20-33. https://doi.org/10.1002/cjas.1411

Atzmüller, C., \& Steiner, P.M. (2010). Experimental Vignette Studies in Survey Research. Methodology. Methodology, 6, 128-138. https://doi.org/10.1027/1614-2241/a000014

Badaracco, J. L., \& Webb, A. P. (1995). Business Ethics: A View from the Trenches. California Management Review, 37, 8-28. https://doi.org/10.2307\%2F41165786

Baker, D. F. (2017). Teaching Empathy and Ethical Decision Making in Business Schools. Journal of Management Education, 41, 575-598. https://doi.org/10.1177\%2F1052562917699028

Barling, J., \& Charbonneau, D. (1992). Disentangling the Relationship between the Achievement Striving and Impatience-Irritability Dimensions of Type A Behavior, Performance and Health. Journal of Organizational Behavior, 13, 369-377. https://doi.org/10.1002/job.4030130405

Baron, R. A. (1989). Personality and Organizational Conflict: Effects of the Type A Behavior Pattern and Self-Monitoring. Organizational Behavior and Human Decision Processes, 44, 281-296. https://doi.org/10.1016/0749-5978(89)90028-9

Belle, N., \& Cantarelli, P. (2017). What Causes Unethical Behavior? A Meta-Analysis to Set an Agenda for Public Administration Research. Public Administration Review, 77, 327-339. https://doi.org/10.1111/puar.12714

Ben-Zur, H., \& Wardi, N. (1994). Type A Behavior and Decision Making Strategies. Personality and Individual Differences, 17, 323-334. https://doi.org/10.1016/0191-8869(94)90280-1

Bermúdez, J., Pérez-Garcia, A. M., \& Sánchez-Elvira, M. A. (1990). Type A Behavior Pattern and Attentional Performance. Personality and Individual Differences, 11, 13-18. https://doi.org/10.1016/0191-8869(90)90163-L

Bishop, E. G., Hailey, B. J., \& O’Rourke, D. (1989). Reliability of the Jenkins Activity Survey-Form T: Temporal Stability and Internal Consistency. Journal of Personality As 
sessment, 53, 60-65. https://doi.org/10.1207/s15327752jpa5301 7

Bluen, S. D., Barling, J., \& Burns, W. (1990). Predicting Sales Performance, Job Satisfaction, and Depression by Using the Achievement Strivings and Impatience-Irritability Dimensions of Type A Behavior. Journal of Applied Psychology, 75, 212-216. https://doi.apa.org/doi/10.1037/0021-9010.75.2.212

Brown, M. E., \& Treviño, L. K. (2006). Ethical Leadership: A Review and Future Directions. The Leadership Quarterly, 17, 595-616. https://doi.org/10.1016/j.leaqua.2006.10.004

Brown, T. A., Sautter, J. A., Littvay, L., Sautter, A. C., \& Bearnes, B. (2010). Ethics and Personality: Empathy and Narcissism as Moderators of Ethical Decision Making in Business Students. Journal of Education for Business, 85, 203-208. https://doi.org/10.1080/08832320903449501

Bryant, F. B., \& Yarnold, P. R. (1995). Comparing Five Alternative Factor Models of the Student Jenkins Activity Survey: Separating the Wheat from the Chaff. Journal of Personality Assessment, 64, 145-158. https://doi.org/10.1207/s15327752jpa6401 10

Bryant, F. B., \& Yarnold, P. R. (2014a). Finding Joy in the Past, Present, and Future: The Relationship between Type A Behavior and Savoring Beliefs Among College Undergraduates. Optimal Data Analysis, 3, 36-41.

Bryant, F. B., \& Yarnold, P. R. (2014b). Type A Behavior and Savoring among College Undergraduates: Enjoy Achievements Now-Not Later. Optimal Data Analysis, 3, 25-27.

Bryant, F. B., \& Yarnold, P. R. (2014c). Type A Behavior, Pessimism and Optimism among College Undergraduates. Optimal Data Analysis, 3, 32-35.

Buchholtz, A. K., \& Carroll, A. B. (2012). Business \& Society: Ethics and Stakeholder Management (8th ed.). South-Western Cengage Learning.

Burns, W., \& Bluen, S. (1992). Assessing a Multidimensional Type A Behaviour Scale. Personality and Individual Differences, 13, 977-986. https://doi.org/10.1016/0191-8869(92)90131-8

Byrne, K. A., Silasi-Mansat, C. D., \& Worthy, D. A. (2015). Who Chokes under Pressure? The Big Five Personality Traits and Decision-Making under Pressure. Personality and Individual Differences, 74, 22-28. https://doi.org/10.1016/j.paid.2014.10.009

Caruso, E. M., \& Gino, F. (2011). Blind Ethics: Closing One’s Eyes Polarizes Moral Judgments and Discourages Dishonest Behavior. Cognition, 118, 280-285.

https://doi.org/10.1016/j.cognition.2010.11.008

Carver, C. S. (1980). Perceived Coercion, Resistance to Persuasion, and the Type A Behavior Pattern. Journal of Research in Personality, 14, 467-481. https://doi.org/10.1016/0092-6566(80)90005-7

Chamberlain, K., \& Zika, S. (1990). The Minor Events Approach to Stress: Support for the Use of Daily Hassles. British Journal of Psychology, 81, 469-481. https://doi.org/10.1111/j.2044-8295.1990.tb02373.x

Chan, S., \& Leung, P. (2006). The Effects of Accounting Students' Ethical Reasoning and Personal Factors on Their Ethical Sensitivity. Managerial Auditing Journal, 21, 436-457. https://doi.org/10.1108/02686900610661432

Chinaveh, M. (2014). A comparison of Type-A and Type-B Learners in the perception of stress Level and Use of Coping Responses in the Campus. Procedia-Social and Behavioral Sciences, 143, 384-388. https://doi.org/10.1016/j.sbspro.2014.07.499

Craft, J. L. (2013). A Review of the Empirical Ethical Decision-Making Literature: 20042011. Journal of Business Ethics, 117, 221-259.

https://doi.org/10.1007/s10551-012-1518-9 
Day, A. L., \& Jreige, S. (2002). Examining Type A Behavior Pattern to Explain the Relationship between Job Stressors and Psychosocial Outcomes. Journal of Occupational Health Psychology, 7, 109-120. https://doi.apa.org/doi/10.1037/1076-8998.7.2.109

Dror, I. E., Busemeyer, J. R., \& Basola, B. (1999). Decision Making under Time Pressure: An Independent Test of Sequential Sampling Models. Memory \& Cognition, 27, 713-725. https://doi.org/10.3758/BF03211564

Feinleib, M., Brand, R. J., Remington, R., \& Zyzanski, S. J. (1978) Section Summary: Association of the Coronary-Prone Behavior Pattern and Coronary Heart Disease. In: T. M. Dembroski, S. M. Weiss, J. L. Shields, S. G. Haynes, \& M. Feinleib (Eds.), Coronary-Prone Behavior (pp. 2-9). Springer.

Ferris, G. R., Dulebohn, J. H., Frink, D. D., George-Falvy, J., Mitchell, T. R., \& Matthews, L. M. (1997). Job and Organizational Characteristics, Accountability, and Employee Influence. Journal of Managerial Issues, 9, 162-175.

Gawronski, B., \& Beer, J. (2017). What Makes Moral Dilemma Judgments “Utilitarian” or "Deontological"? Social Neuroscience, 12, 626-632.

Glass, D. C. (1977). Behavior Patterns, Stress, and Coronary Heart Disease. Erlbaum.

Glass, D. C. (1980) Stress, Behavior Patterns, and Coronary Disease. In K. R. Blankstein, P. Pliner, \& J. Polivy (Eds.) Assessment and Modification of Emotional Behavior (Vol. 6, pp. 196-219). Springer. https://doi.org/10.1007/978-1-4684-3782-9 9

Grimm, L. G., \& Yarnold, P. R. (1984). Performance standards and the Type A behavior pattern. Cognitive Therapy and Research, 8, 59-66. https://doi.org/10.1007/BF01315098

Haines, R., \& Leonard, L. N. (2007). Individual Characteristics and Ethical Decision-Making in an IT Context. Industrial Management \& Data Systems, 107, 5-20. https://doi.org/10.1108/02635570710719025

Harding, C. M., \& O’Looney, B. A. (1986). A Note on the Jenkins Activitiy Survey. Personality and Individual Differences, 7, 409-414. https://doi.org/10.1016/0191-8869(86)90016-4

Hart, K. E. (1997). A Moratorium on Research Using the Jenkins Activity Survey for Type A Behavior? Journal of Clinical Psychology, 53, 905-907. https://doi.org/10.1002/(SICI)1097-4679(199712)53:8\%3C905::AID-JCLP15\%3E3.0.CO i2-O

Hunt, S. D., \& Vitell, S. (1986). A General Theory of Marketing Ethics. Journal of Macromarketing, 6, 5-16. https://doi.org/10.1177\%2F027614678600600103

Jamnik, A. (2011). The Challenges of Business Ethics-Management and The question of Ethics. Tourism \& Hospitality Management, 17, 141-152. https://doi.org/10.20867/thm.17.1.11

Jenkins, C. D., Rosenman, R. H., \& Friedman, M. (1967). Development of an Objective Psychological Test for the Determination of the Coronary-Prone Behavior Pattern in Employed Men. Journal of Chronic Diseases, 20, 371-379. https://doi.org/10.1016/0021-9681(67)90010-0

Jenkins, C. D., Zyzanski, S. J., \& Rosenman, R. H. (1971). Progress Toward Validation of a Computer-Scored Test for the Type A Coronary-Prone Behavior Pattern. Psychosomatic Medicine, 33, 193-202. https://doi.org/10.1097/00006842-197105000-00001

Jeong, S. S., Sun, C., \& Fu, P. P. (2020). Softening the Hearts of Business Students: The Role of Emotions in Ethical Decision Making. Journal of Management Education, 44, 278-312. https://doi.org/10.1177\%2F1052562919895039

Jones, T. (1991). Ethical Decision Making by Individuals in Organizations: An Issue-Contingent Model. Academy of Management Review, 16, 366-395. 


\section{https://doi.org/10.5465/amr.1991.4278958}

Knights, D., \& O'Leary, M. (2005). Reflecting on Corporate Scandals: The Failure of Ethical Leadership. Business Ethics: A European Review, 14, 359-366. https://doi.org/10.1111/j.1467-8608.2005.00417.x

Kocher, M. G., \& Sutter, M. (2006). Time Is Money-Time Pressure, Incentives, and the Quality of Decision-Making. Journal of Economic Behavior \& Organization, 61, 375-392. https://doi.org/10.1016/j.jebo.2004.11.013

Koh, H. P., Scully, G., \& Woodliff, D. R. (2011). The Impact of Cumulative Pressure on Accounting Students' Propensity to Commit Plagiarism: An Experimental Approach. Accounting and Finance, 51, 985-1005. https://doi.org/10.1111/j.1467-629X.2010.00381.x

Koh, H. P., Scully, G., \& Woodliff, D. R. (2018). Can Anticipating Time Pressure Reduce the Likelihood of Unethical Behavior? Journal of Business Ethics, 153, 197-213. https://doi.org/10.1007/s10551-016-3352-y

Krantz, D. S., Glass, D. C., \& Snyder, M. L. (1974). Helplessness, Stress Level, and the Coronary-Prone Behavior Pattern. Journal of Experimental Social Psychology, 10, 284300. https://doi.org/10.1016/0022-1031(74)90074-2

Kühnel, J., Sonnentag, S., \& Bledow, R. (2012). Resources and Time Pressure as Day-Level Antecedents of Work Engagement. Journal of Occupational and Organizational Psychology, 85, 181-198. https://doi.org/10.1111/j.2044-8325.2011.02022.x

Latan, H., Jabbour, C. J., \& Jabbour, A. B. (2019). Ethical Awareness, Ethical Judgment and Whistleblowing: A Moderated Mediation Analysis. Journal of Business Ethics, 155, 289-304. https://doi.org/10.1007/s10551-017-3534-2

Lee, C., Ashford, S. J., \& Jamieson, L. F. (1993). The Effects of Type A Behavior Dimensions and Optimism on Coping Strategy, Health, and Performance. Journal of Organizational Behavior, 14, 143-157. https://doi.org/10.1002/job.4030140205

Marquardt, N. (2010). Implicit Mental Processes in Ethical Management Behavior. Ethics \& Behavior, 20, 128-148. https://doi.org/10.1080/10508421003595950

Marquardt, N., \& Hoeger, R. (2009). The Effect of Implicit Moral Attitudes on Managerial Decision-Making: An Implicit Social Cognition Approach. Journal of Business Ethics 85, 157-171. https://doi.org/10.1007/s10551-008-9754-8

Matthews, K. (1982). Psychological Perspectives on the Type A Behavior Pattern. Psychological Bulletin, 91, 293-323. https://doi.org/10.1037/0033-2909.91.2.293

Matthews, K. A., Krantz, D. S., Dembroski, T. D., \& MacDougall, J. M. (1982). Unique and Common Variance in Structured Interview and Jenkins Activity Survey Measures of the Type A Behavior Pattern. Journal of Personality and Social Psychology, 42, 303313. https://doi.org/10.1037//0022-3514.42.2.303

Maule, A. J., \& Edland, A. C. (1997). The Effects of Time Pressure on Judgment and Decision Making. In R. Ranyard, W. R. Crozier, \& O. Svenson (Eds.), Decision Making: Cognitive Models and Explanation (pp. 189-204). Routledge \& Kegan Paul.

Maule, A. J., Hockey, G. R., \& Bdzola, L. (2000). Effects of Time Pressure on DecisionMaking under Uncertainty: Changes in Affective State and Information Processing Strategy. Acta Psychologica, 104, 283-301. https://doi.org/10.1016/S0001-6918(00)00033-0

May, D., \& Pauli, K. (2002). The Role of Moral Intensity in Ethical Decision Making. Business \& Society, 41, 117-184. https://doi.org/10.1177\%2F0007650302041001006

McCrum, D. (2020, June 25). Wirecard: The Timeline. Financial Times. https://www.ft.com/content/284fblad-ddc0-45df-a075-0709b36868db 
McMahon, J. M., \& Harvey, R. J. (2007). The Effect of Moral Intensity on Ethical Judgment. Journal of Business Ethics, 72, 335-357. https://doi.org/10.1007/s10551-006-9174-6

Moberg, D. T. (2000). Time Pressure and Ethical Decision-Making: The Case for Moral Readiness. Business \& Professional Ethics Journal, 19, 41-67. https://doi.org/10.5840/bpej200019214

Moore, C., \& Gino, F. (2015). Approach, Ability, Aftermath: A Psychological Process Framework of Unethical Behavior at Work. Academy of Management Annals, 9, 235289.

Musbah, A., Cowton, C. J., \& Tyfa, D. (2016). The Role of Individual Variables, Organizational Variables and Moral Intensity Dimensions in Libyan Management Accountants' Ethical Decision Making. Journal of Business Ethics, 134, 335-358.

https://doi.org/10.1007/s10551-014-2421-3

O'Fallon, M.J., \& Butterfield, K. (2005). A Review of the Empirical Ethical DecisionMaking Literature: 1996-2003. Journal of Business Ethics, 59, 375-413. https://doi.org/10.1007/s10551-005-2929-7

Ordóñez, L., \& Benson III, L. (1997). Decision under Time Pressure: How Time Constraint Affects Risky Decision Making. Organizational Behavior and Human Decision Processes, 71, 121-140. https://doi.org/10.1006/obhd.1997.2717

Paolillo, J. G. P., \& Vitell, S. J. (2002). An Empirical Investigation of the Influence of Selected Personal, Organizational and Moral Intensity Factors on Ethical Decision Making. Journal of Business Ethics, 35, 65-74. https://doi.org/10.1023/A:1012648521593

Pérez-Garcia, A. M., \& Sanjuán, P. (1996). Type-A Behaviour Pattern’s (Global and Main Components) Attentional Performance, Cardiovascular Reactivity, and Causal Attributions in the Presence of Different Levels of Interference. Personality and Individual Differences, 20, 81-93. https://doi.org/10.1016/0191-8869(95)00134-R

Prem, R., Ohly, S., Kubicek, B., \& Korunka, C. (2017). Thriving on Challenge Stressors? Exploring Time Pressure and Learning Demands as Antecedents of Thriving at Work. Journal of Organizational Behavior, 38, 108-123. https://doi.org/10.1002/job.2115

Rayburn, J. M., \& Rayburn, L. G. (1996). Relationship between Machiavellianism and Type A Personality and Ethical-Orientation. Journal of Business Ethics, 15, 1209-1219. https://doi.org/10.1007/BF00412819

Rest, J. R. (1986). Moral Development: Advances in Research and Theory. Praeger.

Rosenman, R. H. (1978) The Interview Method of Assessment of the Coronary-Prone Behavior Pattern. In T. M. Dembroski, S. M. Weiss, J. L. Shields, S. G. Haynes, \& M. Feinleib (Eds.), Coronary-Prone Behavior (pp. 55-69). Springer. https://doi.org/10.1007/978-3-642-86007-2 4

Roxburgh, S. (2004). There Just Aren't Enough Hours in the Day: The Mental Health Consequences of Time Pressure. Journal of Health and Social Behavior, 45, 115-131. https://doi.org/10.1177\%2F002214650404500201

Selart, M., \& Johansen, S. T. (2010). Ethical Decision Making in Organizations: The Role of Leadership Stress. Journal of Business Ethics, 99, 129-143. https://doi.org/10.1007/s10551-010-0649-0

Shafer, W. E., Morris, R., \& Ketchand, A. A. (2001). Effects of Personal Values on Auditors' Ethical Decisions. Accounting, Auditing \& Accountability Journal, 14, 254-277. https://doi.org/10.1108/EUM0000000005517

Shawyer, T. J., Clements, L. H., \& Sennetti, J. T. (2015). How Does Moral Intensity Impact the Moral Judgements and Whistleblowing Intentions of Professional Accountants? Research on Professional Responsibility and Ethics in Accounting, 19, 27-60. 
https://doi.org/10.1108/S1574-076520150000019002

Sims, R. L., \& Keon, T. L. (1999). Determinants of Ethical Decision Making: The Relationship of the Perceived Organizational Environment. Journal of Business Ethics, 19, 393401. https://doi.org/10.1023/A:1005834129122

Sims, R. L., \& Keon, T. L. (2000). The Influence of Organizational Expectations on Ethical Decision Making Conflict. Journal of Business Ethics, 23, 219-228. https://doi.org/10.1023/A:1006040109517

Sims, R. R. (1992). The Challenge of Ethical Behavior in Organizations. Journal of Business Ethics, 11, 505-513. https://doi.org/10.1007/BF00881442

Singhapakdi, A., Vitell, S., \& Kraft, K. (1996). Moral Intensity and Ethical DecisionMaking of Marketing Professionals. Journal of Business Research, 36, 245-255. https://doi.org/10.1016/0148-2963(95)00155-7

Spence, J. T., Helmreich, R. L., \& Pred, R. S. (1987). Impatience versus Achievement Strivings in the Type A Pattern: Differential Effects on Students' Health and Academic Achievement. Journal of Applied Psychology, 72, 522-528. https://doi.apa.org/doi/10.1037/0021-9010.72.4.522

Stenmark, C. K., Antes, A. L., Wang, X., Caughron, J. J., Thiel, C. E., \& Mumford, M. D. (2010). Strategies in Forecasting Outcomes in Ethical Decision-Making: Identifying and Analyzing the Causes of the Problem. Ethics \& Behavior, 20, 110-127.

https://doi.org/10.1080/10508421003595935

Storbeck, O. (2020, August 25). Wirecard: The Frantic Final Months of a Fraudulent Operation. Financial Times.

https://www.ft.com/content/6a660a5f-4e8c-41d5-b129-ad5bf9782256

Strube, M. J., \& Werner, C. (1985). Relinquishment of Control and the Type A Behavior Pattern. Journal of Personality and Social Psychology, 48, 688-701. https://doi.apa.org/doi/10.1037/0022-3514.48.3.688

Strube, M. J., Berry, J. M., \& Moergen, S. (1985). Relinquishment of Control and the Type A Behavior Pattern: The Role of Performance Evaluation. Journal of Personality and Social Psychology, 49, 831-842. https://doi.org/10.1037/0022-3514.49.3.831

Sütfeld, L., Gast, R., König, P., \& Pipa, G. (2017). Using Virtual Reality to Assess Ethical Decisions in Road Traffic Scenarios: Applicability of Value-of-Life-Based Models and Influences of Time Pressure. Frontiers in Behavioral Neuroscience, 11, Article No. 122. https://doi.org/10.3389/fnbeh.2017.00122

Sweeney, B., \& Costello, F. (2009). Moral Intensity and Ethical Decision-Making: An Empirical Examination of Undergraduate Accounting and Business Students. Accounting Education, 18, 75-97. https://doi.org/10.1080/09639280802009454

Teuchmann, K., Totterdell, P., \& Parker, S. K. (1999). Rushed, Unhappy, and Drained: An Experience Sampling Study of Relations Between Time Pressure, Perceived Control, Mood, and Emotional Exhaustion in a Group of Accountants. Journal of Occupational Health Psychology, 4, 37-54. https://doi.org/10.1037/1076-8998.4.1.37

Thoresen, C., \& Powell, L. (1992). Type A Behavior Pattern: New Perspectives on Theory, Assessment, and Intervention. Journal of Consulting and Clinical Psychology, 60, 595604. https://doi.org/10.1037/0022-006X.60.4.595

Valdesolo, P., \& DeSteno, D. (2006). Manipulations of Emotional Context Shape Moral Judgment. Psychological Science, 17, 476-477.

https://doi.org/10.1111\%2Fj.1467-9280.2006.01731.x

Vera-Villarroel, P., \& Sánchez, A. (2004). Analysis of the Relationship between the Type A Behavior Pattern and Fear of Negative Evaluation. International Journal of Clinical and Health Psychology, 4, 313-322. 
Verbeke, W., Ouwerkerk, C., \& Peelen, E. (1996). Exploring the Contextual and Individual Factors on Ethical Decision Making of Salespeople. Journal of Business Ethics, 15, 1175-1187. https://doi.org/10.1007/BF00412816

Verplanken, B. (1993). Need for Cognition and External Information Search: Responses to Time Pressure during Decision-Making. Journal of Research in Personality, 27, 238252. https://doi.org/10.1006/jrpe.1993.1017

Yarnold, P. R. (2014). UniODA vs. Kappa: Evaluating the Long-Term (27-Year) TestRetest Reliability of the Type A Behavior Pattern. Optimal Data Analysis, 3, 14-16.

Yarnold, P. R., Mueser, K. T., Grau, B. W., \& Grimm, L. G. (1986). The Reliability of the Student Version of the Jenkins Activity Survey. Journal of Behavioral Medicine, 9, 401414. https://doi.org/10.1007/BF00845123

Zajonz, D. (2020, July 29). Darum geht es im Wirecard-Skandal. Tagesschau.

Zakay, D., \& Wooler, S. (1984). Time Pressure, Training and Decision Effectiveness. Ergonomics, 27, 273-284. https://doi.org/10.1080/00140138408963489

Zuzanek, J. (2004). Work, Leisure, Time-Pressure and stress. In J. T. Haworth, \& A. J. Veal (Eds.), Work and Leisure (pp. 123-144). Routledge.

Zyzanski, S. J., \& Jenkins, C. D. (1970). Basic Dimensions Within the Coronary-Prone Behavior Pattern. Journal of Chronic Diseases, 22, 781-795.

https://doi.org/10.1016/0021-9681(70)90080-9 